OPEN ACCESS

Edited by:

Marco Carotenuto,

University of Campania Luigi

Vanvitelli, Italy

Reviewed by:

Maria Ruberto,

Santa Maria del Pozzo, Italy

Michele Roccella,

University of Palermo, Italy

*Correspondence:

Ming Yang

yangming19710217@163.com

Xuming Mo

mohsuming15@sina.com

${ }^{\dagger}$ These authors have contributed equally to this work and share first authorship

Specialty section: This article was submitted to

Pediatric Neurology, a section of the journal

Frontiers in Neurology

Received: 27 March 2020 Accepted: 09 June 2020

Published: 17 July 2020

Citation

Ma S, Li Y, LiU Y, Xu C, Li H, Yao Q, Wang $Y$, Yang $Z$, Zuo $P$, Yang $M$ and

Mo $X$ (2020) Changes in Cortical Thickness Are Associated With

Cognitive Ability in Postoperative

School-Aged Children With Tetralogy of Fallot. Front. Neurol. 11:691. doi: 10.3389/fneur.2020.00691

\section{Changes in Cortical Thickness Are Associated With Cognitive Ability in Postoperative School-Aged Children With Tetralogy of Fallot}

\author{
Siyu Ma ${ }^{1 \dagger}$, Yaping $\mathrm{Li}^{1 \dagger}$, Yuting $\mathrm{Liu}^{2}$, Cheng $\mathrm{Xu}^{1}$, Huijun $\mathrm{Li}^{2}$, Qiong $\mathrm{YaO}^{2}$, Ying Wang ${ }^{2}$, \\ Zhaocong Yang ${ }^{1}$, Pengcheng Zuo ${ }^{1}$, Ming Yang ${ }^{2 *}$ and Xuming Mo ${ }^{1 *}$
}

${ }^{1}$ Department of Cardiothoracic Surgery, Children's Hospital of Nanjing Medical University, Nanjing, China, ${ }^{2}$ Department of Radiology, Children's Hospital of Nanjing Medical University, Nanjing, China

In children with tetralogy of Fallot (TOF), there is a risk of brain injury even if intracardiac deformities are corrected. This population follow-up study aimed to identify the correlation between cerebral morphology changes and cognition in postoperative school-aged children with TOF. Resting-state functional magnetic resonance imaging (rs-fMRI) and the Wechsler Intelligence Scale for Children-Chinese revised edition (WISC-CR) were used to assess the difference between children with TOF and healthy children (HCs). Multiple linear regression showed that the TOF group had a lower verbal intelligence quotient $(\mathrm{VIQ}, 95.000 \pm 13.433, p=0.001$ ) than the $\mathrm{HC}$ group and that $\mathrm{VIQ}$ had significant positive correlations with the cortical thickness of both the left precuneus $(p<0.05)$ and the right caudal middle frontal gyrus $(p<0.05)$ after adjustment for preoperative SpO2, preoperative systolic blood pressure (SBP), preoperative diastolic blood pressure (DBP) and time of aortic override $(\mathrm{AO})$. Our results suggested that brain injury induced by TOF would exert lasting effects on cortical and cognitive development at least to school age. This study provides direct evidence of the relationship between cortical thickness and VIQ and of the need for strengthened verbal training in school-aged TOF patients after corrective surgery.

\section{Keywords: tetralogy of fallot, cerebral cortical thickness, cognition, VIQ, brain injury}

\section{INTRODUCTION}

Tetralogy of Fallot (TOF) is a common cyanotic congenital heart disease (CHD) (1), accounting for almost 3.5\% of CHD cases (2). TOF is mainly characterized by a ventricular septal defect (VSD), right ventricular outflow track obstruction, aortic override $(\mathrm{AO})$ and right ventricular hypertrophy (3), all of which cause haemodynamic abnormalities that lead to a series of events including hypoxia episodes, brain abscesses, atrial fibrillation and cerebrovascular accidents (4). Under $1 \%$ of TOF patients who do not have surgery survive to 40 years old (5), whereas, those who undergo surgery before 5 years old have a 30 -year survival rate of $90 \%$ (6). However, although mortality declines after surgery, survivors still face a variety of complications (7), such as myocardial damage (2), pulmonary incompetence (8), aortic dilation and arrhythmias (9). Furthermore, over 50\% of TOF patients also exhibit cerebral damage (10), which may manifest as declines in cognitive, psychosocial, and behavioral ability $(11,12)$ and influence the patients' long-term quality of life (13). 
Brain injury in TOF patients is an important concern (14). Children with TOF may suffer from brain injury in the prenatal (15), postpartum preoperative, perioperative (16), and postoperative periods due to genetic mutations, brain blood flow disturbances, cardiopulmonary bypass (CPB) (17, 18), anesthesia procedures (19), low cardiac output (LCO) (20) and socioeconomic status (SES) $(21,22)$. Of these time periods, the prenatal and postpartum preoperative periods are considered to carry the highest risk of brain injury $(23,24)$; additionally, they overlap with a critical period of cerebral development $(25,26)$. Fortunately, with advances in neuroimaging technology, brain injuries in children with CHDs are frequently identified early by magnetic resonance imaging (MRI) $(27,28)$; these brain injuries include delayed cerebral maturation (29), brain volume decline (30), white matter injury (WMI) (31), and stroke (32). In addition, delayed cortical development has been reported in CHD fetuses and neonates; the manifestations include delayed cortical folding, cortical depth asymmetry and reduced cortical thickness (25, 33). However, those studies describe only preoperative and short-term postoperative morphological changes. It remains for additional research to trace long-term cortical changes and further examine the association between cortical changes and cognition.

The effects of cortical changes on the cognitive ability of postoperative children with TOF remain unclear. Therefore, we examined the cerebral morphology of postoperative TOF patients via $\mathrm{MRI}$, evaluated their cognitive abilities and further analyzed the correlation between them. Interestingly, the results showed that the cortical thickness values of both the left precuneus and the right caudal middle frontal cortex had significant positive correlations with verbal intelligence quotient (VIQ).

\section{MATERIALS AND METHODS}

\section{Subjects}

From November 2015 to June 2016, 13 school-aged children with TOF were validated for participation, and informed consent was obtained from their legal guardians on their behalf. Ten of those children eventually completed resting-state functional magnetic resonance imaging (rs-fMRI) examination, and the data fulfilled the criteria for further analysis. Every participating child with TOF underwent corrected surgery in Nanjing Children's Hospital of Nanjing Medical University and had no known hereditary syndromes or central nervous system diseases, such as Down syndrome, cerebral tumors or craniocerebral trauma. The control group consisted of 13 healthy children (HCs) who were matched with the TOF group by age, gender, and education level and had no cardiovascular or nervous system diseases; informed consent was acquired from the children's legal guardians. All participants were right-handed and had no contraindications to MRI, such as implanted pacemakers or claustrophobia.

\section{Rs-fMRI Data Acquisition}

MRI data were acquired from all participants using a Siemens MAGNETOM Avanto 1.5 T MRI machine with a standard 12-channel head coil. Subjects lay supine with sponge plugs in the external auditory canals to reduce the effect of scanner noise, and they were requested to lie awake quietly with their eyes closed and avoid thinking. When questioned afterward, all of the participants confirmed that they had not fallen asleep in the scanner. During the scans, each subject's head was braced with foam padding to reduce movement artifacts.

The scanning sequences are as follows: (1) Fluid-attenuated inversion recovery (FLAIR): the thickness was $5 \mathrm{~mm}$, and there were no gaps between slices. The repetition time (TR) was $1,200 \mathrm{~ms}$, and the echo time (TE) was $28 \mathrm{~ms}$. The matrix size was $512 * 464$. The total number of layers was 20 . Intracranial lesions were identified and excluded by experienced radiologists. (2) T1-weighted imaging (T1WI): a three-dimensional magnetization prepared rapid gradient echo (3D-MP-RAGE) imaging sequence was used. TR was $1,900 \mathrm{~ms}$, and TE was $2.48 \mathrm{~ms}$. The turning angle was $9^{\circ}$. The field of view (FOV) was $256^{*} 256 \mathrm{~mm}$, and the matrix size was $256^{*} 256$. The protocol included 176 slices with a thickness of $1 \mathrm{~mm}$ each, and there were no gaps between slices. The T1WI scans were reconstructed into 3D images with a slice thickness of $4 \mathrm{~mm}$ and no space between slices. (3) Resting blood oxygenation level-dependent (BOLD) scan: gradient-echo echo-planar imaging (GRE-EPI) was applied. TR was 2,000 ms, and TE was $25 \mathrm{~ms}$. The turning angle was $90^{\circ}$. The FOV was $240^{*} 240 \mathrm{~mm}$, and the matrix size was $64^{*} 64$. The slice thickness was $5 \mathrm{~mm}$, with $2 \mathrm{~mm}$ spacing. The total number of slices was 36 , and the scanning time was $6 \mathrm{~min}$.

\section{Rs-fMRI Data Pre-processing}

Data in this experiment were preprocessed with Data Processing Assistant for rs-fMRI (34) (DPARSF, http://www.restfmri.net) on the MATLAB platform.

The steps were as follows:

(1) A total of 180 time points were collected by BOLD in this experiment. In order to reduce the influence of MRI magnetic field instability and noise during the initial scan, data from the first 10 time points were removed.

(2) Slice-timing correction was carried out for the remaining time points so that all images collected at one time would be temporally aligned.

(3) Correct head movements (including translation and rotation in $3 \mathrm{D}$ space). Considering the long scan time and the influence of magnetic resonance noise, some degree of head movement may occur, causing the haemodynamic response to be obscure. Therefore, it was necessary to correct the head movement of all subjects. Subjects were removed from this study if their head movement exceeded $1 \mathrm{~mm}$ of translation or $1^{\circ}$ of rotation about the $\mathrm{x}, \mathrm{y}$, or $\mathrm{z}$ axis.

(4) Spatial registration and linear detrending. Considering the differences in brain morphology among different subjects, all MRI images were standardized to the same reference space (standard anatomical template for the head, Montreal Neurological Institute, Canada), and the standardized data were then processed to remove linear trends. 
TABLE 1 | Characteristics of TOF and healthy children.

\begin{tabular}{|c|c|c|c|}
\hline \multirow[t]{2}{*}{ Variables } & TOF & $\mathrm{HC}$ & \multirow[t]{2}{*}{$p$-value } \\
\hline & $(n=10)$ & $(n=13)$ & \\
\hline Age (year) & $10.01 \pm 1.88$ & $9.73 \pm 0.77$ & 0.63 \\
\hline Sex (male/female) & $6 / 4$ & $8 / 5$ & 0.94 \\
\hline Education (year) & $2.31 \pm 1.25$ & $2.42 \pm 0.91$ & 0.80 \\
\hline $\begin{array}{l}\text { Household income (Yuan } \\
\text { per month) }\end{array}$ & $6,750.00 \pm 2,214.22$ & $7,192.31 \pm 1,575.05$ & 0.58 \\
\hline Age of surgery (year) & $2.10 \pm 1.69$ & NA & \\
\hline Postoperative time (year) & $7.33 \pm 2.31$ & NA & \\
\hline Hospital stays (day) & $17.38 \pm 5.55$ & NA & \\
\hline Preoperative $\mathrm{SpO}_{2}(\%)$ & $73.29 \pm 16.11$ & NA & \\
\hline $\begin{array}{l}\text { Preoperative SBP } \\
(\mathrm{mmHg})\end{array}$ & $98.57 \pm 11.63$ & NA & \\
\hline $\begin{array}{l}\text { Preoperative DBP } \\
(\mathrm{mmHg})\end{array}$ & $57.57 \pm 9.74$ & NA & \\
\hline Preoperative $\mathrm{pH}$ & $7.34 \pm 0.03$ & NA & \\
\hline CPB time (min) & $61.75 \pm 7.52$ & NA & \\
\hline AO time (min) & $38.52 \pm 5.38$ & NA & \\
\hline
\end{tabular}

Mean $\pm S D$. TOF, tetralogy of Fallot; $\mathrm{HC}$, healthy children; $\mathrm{SpO}_{2}$, saturation of pulse oxygen; SBP, systolic blood pressure; $D B P$, diastolic blood pressure; $\mathrm{pH}$, potential of hydrogen; CPB, cardiopulmonary bypass; $A O$, aortic occlusion; NA, not available. Bold values represents that the results have statistical significance.

(5) Low-frequency filtering. A frequency band of $0.01-0.08 \mathrm{~Hz}$ was used to filter out low-frequency drift.

(6) Spatial smoothing. A Gaussian kernel function with a full width at half maximum (FWHM) of $4 \times 4 \times 4 \mathrm{~mm}^{3}$ was used to perform spatial smoothing of fMRI images.

\section{Cerebral Morphology Analyses}

We used the Computational Anatomy Toolbox (CAT12, http:// dbm.neuro.uni-jena.de/cat/) of SPM12 (https://www.fil.ion.ucl. ac.uk/spm/software/spm12/) to extract morphological indexes of the cortical surface. An image of each subject was produced in a standard position, such that every image had the same origin and spatial direction. Linear and non-linear registration of highresolution T1WI was performed for each patient. The image was divided into gray matter volume (GMV), white matter volume (WMV) and cerebrospinal fluid volume (CSFV). Brain tissue volume (BTV) and total intracranial volume (TIV) could then be calculated.

\section{Intelligence Assessment}

All subjects had their cognitive ability assessed using the Wechsler Intelligence Scale for Children-Chinese revised edition (WISC-CR). The WISC is an authoritative and widely used intelligence scale for children (12). The WISC-CR was suitable for Chinese children between the ages of 6 and 16 years; the test is divided into 12 domains, including common sense, analogies, arithmetic, vocabulary, comprehension, digit span, missing picture completion, picture arrangement, block design, object collocation, decoding, and mazes (of these, digit span and mazes were optional). Each subject's results were scored according to the operating manual and the subject's age. The VIQ
TABLE 2 | Cerebral morphology and intelligence quotient changings in postoperative TOF.

\begin{tabular}{|c|c|c|c|c|}
\hline & & TOF & $\mathrm{HC}$ & $p$-value \\
\hline CSFV & & $246.200 \pm 53.425$ & $266.769 \pm 41.698$ & 0.155 \\
\hline GMV & & $683.800 \pm 75.295$ & $749.692 \pm 42.092$ & 0.007 \\
\hline WMV & & $438.000 \pm 56.978$ & $496.308 \pm 48.340$ & 0.007 \\
\hline BTV & & $1,121.800 \pm 129.049$ & $1246.000 \pm 86.085$ & 0.006 \\
\hline TIV & & $1,368.100 \pm 151.542$ & $1513.154 \pm 111.126$ & 0.007 \\
\hline $\begin{array}{l}\text { Whole } \\
\text { brain } \\
\text { CAT }\end{array}$ & & $2.750 \pm 0.061$ & $2.842 \pm 0.068$ & 0.001 \\
\hline \multicolumn{5}{|c|}{ Left hemisphere CAT } \\
\hline & Inferior temporal & $2.881 \pm 0.138$ & $3.000 \pm 0.149$ & 0.032 \\
\hline & Lateral occipital & $2.016 \pm 0.111$ & $2.123 \pm 0.079$ & 0.007 \\
\hline & Middle temporal & $3.182 \pm 0.089$ & $3.236 \pm 0.145$ & 0.156 \\
\hline & Fusiform & $2.732 \pm 0.135$ & $2.919 \pm 0.153$ & 0.003 \\
\hline & Isthmus cingulate & $2.623 \pm 0.266$ & $2.656 \pm 0.199$ & 0.368 \\
\hline & Precuneus & $2.671 \pm 0.148$ & $2.799 \pm 0.076$ & 0.007 \\
\hline \multicolumn{5}{|c|}{ Right hemisphere CAT } \\
\hline & Superior frontal & $3.286 \pm 0.103$ & $3.346 \pm 0.309$ & 0.282 \\
\hline & Caudal middle frontal & $2.959 \pm 0.141$ & $3.088 \pm 0.101$ & 0.009 \\
\hline $\mathrm{VIQ}$ & & $95.000 \pm 13.433$ & $122.000 \pm 9.138$ & 0.001 \\
\hline $\mathrm{PIQ}$ & & $98.600 \pm 18.014$ & $104.200 \pm 12.755$ & 0.274 \\
\hline FSIQ & & $96.100 \pm 15.286$ & $115.400 \pm 10.213$ & 0.013 \\
\hline
\end{tabular}

Mean $\pm S D$. TOF, tetralogy of Fallot; HC, healthy children; CSFV, cerebrospinal fluid volume; GMV, gray matter volume; WMV, white matter volume; BTV, brain tissue volume; TIV, total intracranial volume; CAT, cortical average thickness; VIQ, verbal intelligence quotient; PIQ, performance intelligence quotient; FSIQ, full scale intelligence quotient. Bold values represents that the results have statistical significance.

was determined from the first six items, and the performance intelligence quotient (PIQ) was determined from the last six items. Finally, the full-scale intelligence quotient (FSIQ) could be calculated.

\section{Statistical Analyses}

We used SPSS 20.0 (IBM Corp., Armonk, NY, USA) to perform the statistical analyses in this study. Continuous variable data are described as the mean \pm SD in Tables 1, 2. Differences between the TOF group and the HC group were shown in some variables by conducting one-sample $t$-tests. Single and multiple linear regression analyses were used to explore the correlation between cortical average thickness of brain regions, intelligence quotient (IQ) and covariates. Statistical significance was considered when the $p<0.05$.

\section{RESULTS}

Table 1 shows the demography of TOF and HC groups. No significant difference was found in age, gender, years of education, or household income. Additionally, the hospital records of the TOF group are summarized.

Differences in cerebral morphology and IQ between the TOF and HC groups are shown in Table 2. Healthy children had higher VIQ (95.000 \pm 13.433$)$ and FSIQ (95.000 \pm 13.433$)$ scores than children with TOF. GMV (683.800 \pm 75.295), 

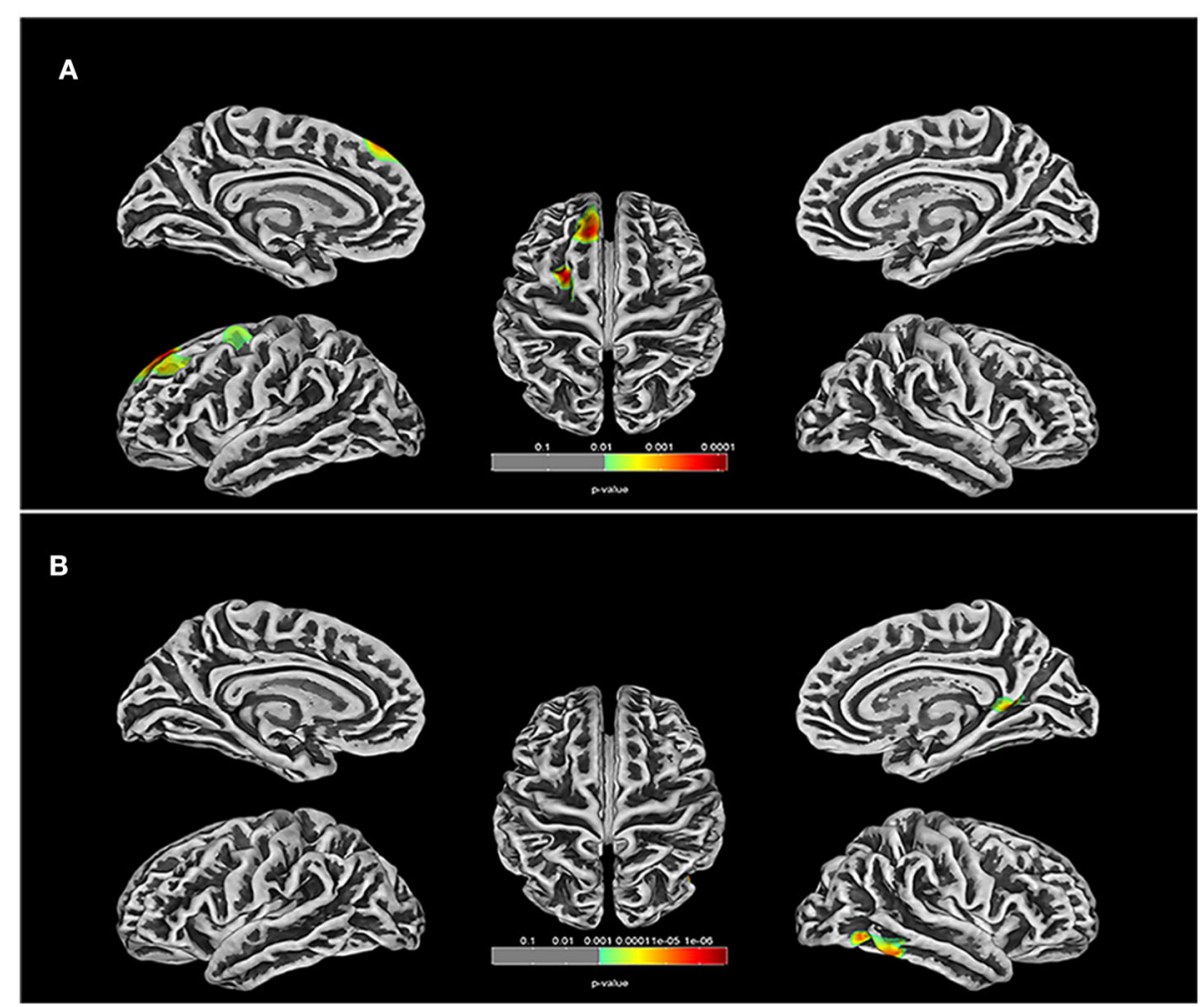

FIGURE 1 | Comparison of cortical thickness in TOF and HC groups. (A) In left hemisphere of TOF group, the cortical thickness of inferior temporal, lateral occipital, middle temporal, fusiform, isthmus cingulate, and precuneus were reduced. (B) TOF children had lower cortical thickness of superior frontal and caudal middle frontal in right hemisphere.

WMV (438.000 \pm 56.978), BTV (1,121.800 \pm 129.049$)$, TIV $(1,368.100 \pm 151.542)$ and whole-brain cortical average thickness (CAT, $2.750 \pm 0.061$ ) were reduced in children with TOF compared with healthy children. Furthermore, Figure 1 shows a $3 \mathrm{D}$ simulation diagram of differences in cortical thickness between the two groups. Reduced left inferior temporal CAT $(2.881 \pm 0.138)$, left lateral occipital CAT $(2.016 \pm 0.111)$, left precuneus CAT $(2.671 \pm 0.148)$ and right caudal middle frontal CAT $(2.959 \pm 0.141)$ were evident in the TOF group.

After analyzing the correlation among cerebral morphology changes, IQ and hospital records (Tables 3, 4), we found that preoperative $\mathrm{SpO}_{2}$, preoperative systolic blood pressure (SBP), preoperative diastolic blood pressure (DBP) and time of AO were related to morphology changes.

In multiple linear regression, left precuneus CAT (beta: 79.905; 95\% CI: 72.226,87.584) and right caudal middle frontal CAT (beta: 143.606; 95\% CI: 25.181,262.030) were related to VIQ after adjusting for preoperative $\mathrm{SpO}_{2}$, preoperative SBP, preoperative DBP and time of AO (Table 5).

\section{DISCUSSION}

Our population follow-up study was the first to identify the relationship between reduced cortical thickness and low VIQ in postoperative school-aged children with TOF, especially in the precuneus of the left hemisphere and caudal middle frontal cortex of the right hemisphere.

The cerebral cortex plays an irreplaceable role in interconnecting brain areas and in sensory, motor and cognitive processing (35) and should be given close attention in postoperative children with TOF. Children with TOF have reduced oxygen delivery and oxygen consumption (36), to which the cerebral cortex is especially vulnerable (25). The main microstructural changes that occur in the hypoxic cerebral are impaired dendritic arborization of neurons (37) and inhibition of glial cell formation $(35,38,39)$. Although hypoxia induced by CHD influences dendritic outgrowth, cortical connectivity, and synapse formation $(40,41)$, few studies have explored the association between cortical alterations and cognition in postoperative children with TOF. Thus, based on our results and published studies, we speculate herein about the underlying mechanism of low VIQ induced by reduced cortical thickness in postoperative school-aged children with TOF.

The precuneus might influence verbal cognition by combining the temporal lobes via the temporoparietal junction (TPJ). The precuneus, part of the posteromedial parietal cortex, is part of the associative cortices (42). The precuneus may be involved in visual-spatial imagery processing, episodic memory retrieval and self-processing operations by mutually connecting with 
the frontal lobe, dorsal premotor area, supplementary motor area, anterior cingulate cortex, and temporoparietooccipital cortex (TPO) (42-44). In addition, many studies have indicated that the precuneus is associated with verbal processing (4547). However, few studies have examined the mechanism by which the precuneus influences verbal cognition. Recently, studies showed that the precuneus and temporal cortex could participate in attention, social cognition and working

TABLE 3 | Pearson correlation between cerebral structure changings and cognitive abilities.

\begin{tabular}{lccc}
\hline & VIQ & PIQ & FSIQ \\
\hline CSFV & 0.058 & -0.345 & -0.202 \\
GMV & 0.453 & $\mathbf{0 . 6 8 7 ^ { * }}$ & $\mathbf{0 . 6 3 3 ^ { * }}$ \\
WMV & 0.392 & 0.464 & 0.457 \\
BTV & 0.438 & 0.605 & 0.571 \\
TIV & 0.395 & 0.395 & 0.416 \\
Whole brain CAT & -0.296 & -0.058 & -0.141 \\
Left inferior temporal CAT & 0.511 & 0.576 & 0.627 \\
Left lateral occipital CAT & $-\mathbf{0 . 9 1 1 ^ { * * }}$ & -0.480 & $-\mathbf{0 . 7 4 9}$ \\
Left middle temporal CAT & -0.388 & -0.556 & -0.480 \\
Left fusiform CAT & 0.219 & -0.213 & -0.023 \\
Left isthmus cingulate CAT & -0.032 & 0.097 & 0.035 \\
Left precuneus CAT & 0.080 & 0.283 & 0.271 \\
Right superior frontal CAT & -0.321 & -0.089 & -0.182 \\
Right caudal middle frontal CAT & 0.060 & 0.119 & 0.143 \\
\hline
\end{tabular}

${ }^{*}$ Correlation is significant at the 0.05 level, ${ }^{*}$ Correlation is significant at the 0.01 level. CSFV, cerebrospinal fluid volume; GMV, gray matter volume; WMV, white matter volume; $B T V$, brain tissue volume; TIV, total intracranial volume; CAT, cortical average thickness; $V I Q$, verbal intelligence quotient; PIQ, performance intelligence quotient; FSIQ, full scale intelligence quotient. Bold values represents that the results have statistical significance. memory by interconnecting via short U-shaped fibers and long connections $(48,49)$, which was contrary to the traditional notion in neuropsychology that the precuneus and temporal cortex function as separate regions (50). Furthermore, the left TPJ showed hyperactivity in patients with auditory verbal hallucinations (AVHs) (49), and the left temporal lobe is related to the language development of children with CHD (51). Thus, we hypothesized that decreased left precuneus cortical thickness could reduce the connection of the temporal lobe via the TPJ and further influence VIQ in postoperative children with TOF.

The middle frontal lobe is known as the secondary language area $(52,53)$, and it is involved in many verbal expression processes, such as verbal and non-verbal fluency (54-56), verbal working memory (57-59), switching (60), and semantics (61). The right frontal lobe mainly participates in orthography of Chinese characters, verbal suppression, verbal strategy use and non-verbal fluency $(54,62,63)$. Our results also provided valid proof that the middle frontal cortex is correlated with verbal cognition. Therefore, we infer that children with TOF had poor performance in verbal expression and led to lower VIQ.

However, our study has some weaknesses. First, a larger sample size would be necessary to make the results more credible. Moreover, this study merely evaluated the overall neurological function of school-aged children after TOF correction and could not identify the specific timing of injuries due to the absence of preoperative MRI results. In addition, it is mainly children with neurological disorders who tend to participate in these programmes, and the results might be biased accordingly. Furthermore, this study reported a correlation between cortical thickness and IQ. The influence of other morphological changes on cognition

TABLE 4 | Pearson correlation between cerebral structure changings and demographic variables.

\begin{tabular}{|c|c|c|c|c|c|c|c|c|c|c|}
\hline & Age & $\begin{array}{c}\text { Hospital } \\
\text { stays }\end{array}$ & $\begin{array}{l}\text { Age of } \\
\text { surgery }\end{array}$ & $\begin{array}{l}\text { Postoperative } \\
\text { time }\end{array}$ & $\begin{array}{l}\text { Preoperative } \\
\mathrm{SpO}_{2}\end{array}$ & $\begin{array}{c}\text { Preoperative } \\
\text { SBP }\end{array}$ & $\begin{array}{l}\text { Preoperative } \\
\text { DBP }\end{array}$ & $\begin{array}{c}\text { Preoperative } \\
\text { pH }\end{array}$ & $\begin{array}{l}\text { CPB } \\
\text { time }\end{array}$ & AO time \\
\hline CSFV & 0.365 & 0.322 & $0.771^{*}$ & -0.346 & 0.653 & 0.206 & 0.350 & 0.103 & -0.098 & -0.592 \\
\hline WMV & -0.228 & -0.282 & 0.320 & -0.410 & 0.633 & 0.245 & -0.235 & -0.138 & -0.201 & -0.053 \\
\hline BTV & -0.363 & -0.396 & 0.309 & -0.496 & 0.695 & 0.261 & -0.102 & 0.036 & -0.201 & -0.145 \\
\hline Left inferior temporal CAT & 0.138 & -0.729 & -0.553 & 0.528 & -0.124 & -0.070 & -0.179 & 0.350 & 0.568 & 0.241 \\
\hline Left lateral occipital CAT & -0.003 & 0.567 & 0.155 & -0.123 & -0.344 & -0.012 & -0.134 & -0.722 & -0.383 & 0.285 \\
\hline Left middle temporal CAT & 0.375 & 0.473 & 0.156 & 0.141 & -0.178 & -0.537 & 0.126 & 0.579 & -0.049 & -0.486 \\
\hline Left fusiform CAT & 0.092 & -0.184 & -0.066 & 0.116 & 0.083 & $0.764^{\star}$ & $0.816^{*}$ & -0.165 & 0.526 & 0.033 \\
\hline Left isthmus cingulate CAT & 0.074 & -0.190 & 0.708 & -0.500 & $0.929^{\star *}$ & 0.198 & 0.471 & 0.598 & -0.032 & $-0.779^{\star}$ \\
\hline
\end{tabular}

${ }^{*}$ Correlation is significant at the 0.05 level. ${ }^{*}$ Correlation is significant at the 0.01 level. CSFV, cerebrospinal fluid volume; GMV, gray matter volume; WMV, white matter volume; BTV, brain tissue volume; TN, total intracranial volume; CAT, cortical average thickness; $\mathrm{SpO}_{2}$, saturation of pulse oxygen; SBP, systolic blood pressure; DBP, diastolic blood pressure; $p H$, potential of hydrogen; $C P B$, cardiopulmonary bypass; $A O$, aortic occlusion. Bold values represents that the results have statistical significance. 
TABLE 5 | Multivariable association of cerebral structure changings and cognitive abilities in TOF postoperative children.

\begin{tabular}{|c|c|c|c|c|}
\hline & \multicolumn{2}{|l|}{ VIQ } & \multicolumn{2}{|l|}{ FSIQ } \\
\hline GMV & $0.199(-2.576,2.974)$ & 0.529 & $0.369(-2.531,3.269)$ & 0.353 \\
\hline WMV & $0.183(-11.191,11.556)$ & 0.872 & $0.618(-14.510,15.746)$ & 0.695 \\
\hline BTV & $0.131(-2.257,2.520)$ & 0.612 & $0.261(-2.439,2.962)$ & 0.435 \\
\hline Whole brain CAT & $290.098(-1,670.986,2,251.182)$ & 0.311 & $471.829(-813.154,1,756.813)$ & 0.134 \\
\hline Left inferior temporal CAT & $51.623(-233.107,336.353)$ & 0.261 & $63.877(-602.372,730.127)$ & 0.438 \\
\hline Left lateral occipital CAT & $-104.201(-694.515,486.113)$ & 0.267 & $-128.442(-1495.279,1238.394)$ & 0.444 \\
\hline Left middle temporal CAT & $-5.064(-2,135.642,2,125.515)$ & 0.981 & $-74.679(-3057.549,2908.192)$ & 0.804 \\
\hline Left fusiform CAT & $-288.834(-1,961.253,1,383.584)$ & 0.272 & $-460.896(-1,344.694,422.902)$ & 0.095 \\
\hline Left isthmus cingulate CAT & $36.404(-1,271.914,1,344.721)$ & 0.784 & $9.942(-2,023.929,2,043.813)$ & 0.961 \\
\hline
\end{tabular}

Adjusted for preoperative $S p O_{2}$, preoperative SBP, preoperative $D B P$ and $A O$ time. CSFV, cerebrospinal fluid volume; GMV, gray matter volume; WMV, white matter volume; BTV, brain tissue volume; TIV, total intracranial volume; CAT, cortical average thickness; $\mathrm{SpO}_{2}$, saturation of pulse oxygen; $S B P$, systolic blood pressure; $D B P$, diastolic blood pressure; $A O$, aortic occlusion; VIQ, verbal intelligence quotient; FSIQ, full scale intelligence quotient; $C l$, confidence interval. Bold values represents that the results have statistical significance.

is expected to be shown in future articles. Finally, this study was based on the preliminary exploration of TOF cases, and functional validation is needed to explore the underlying mechanism.

\section{CONCLUSION}

In this study, the VIQ of postoperative school-aged children with TOF was lower than that of healthy children of similar age and was correlated with reduced cortical thickness of the precuneus in the left hemisphere and the caudal middle frontal cortex in the right hemisphere. The results implied that brain damage before the correction of intracardiac deformity continuously influenced the cortical development and cognitive abilities of children with TOF, at least to school age. The underlying mechanisms might consist of delayed language development affected by left precuneustemporal connections and poor verbal expression induced by right middle frontal cortex dysfunction. Therefore, even if the intracardiac deformities of TOF patients are corrected, the possibility of brain injury should also be given close attention after surgery. Furthermore, language expression training for children with TOF should be strengthened after corrective surgery.

\section{DATA AVAILABILITY STATEMENT}

The original contributions presented in the study are included in the article/supplementary material, further inquiries can be directed to the corresponding author/s.

\section{ETHICS STATEMENT}

The studies involving human participants were reviewed and approved by the Ethics Committee of Children's hospital of Nanjing Medical University. Written informed consent to participate in this study was provided by the participants' legal guardian/next of kin. Written informed consent was obtained from the individual(s), and minor(s)' legal guardian/next of kin, for the publication of any potentially identifiable images or data included in this article.

\section{AUTHOR CONTRIBUTIONS}

$\mathrm{XM}$ and MY designed this study protocol. YLi collected the information of population. HL, QY, and YW scanned the participants by MRI. CX, YLiu, and SM performed the data analysis under the close supervision of $\mathrm{ZY}, \mathrm{PZ}, \mathrm{MY}$, and XM. The manuscript was drafted by SM and proofread by CX. All authors contributed to the article and approved the submitted version.

\section{FUNDING}

This work was supported by the National Natural Science Foundation of China (81970265); Clinical Frontier Technology of Clinical Medicine of Jiangsu Provincial Science and Technology Department (BE2017608); Science and Technology Development Fund of Nanjing Medical University (NMUB2019192); and Sub-project of Major Chronic Non-Communicable Diseases Prevention and Control Research Key Project of National Key Research and Development Plan (2017YFC1308105). 


\section{REFERENCES}

1. Hokanson JS, Moller JH. Adults with tetralogy of fallot: long-term follow-up. Cardiol Rev. (1999) 7:149-55. doi: 10.1097/00045415-199905000-00012

2. Apitz C, Webb GD, Redington AN. Tetralogy of fallot. Lancet. (2009) 374:1462-71. doi: 10.1016/S0140-6736(09)60657-7

3. Pinsky WW, Arciniegas E. Tetralogy of fallot. Pediatr Clin North Am. (1990) 37:179-92. doi: 10.1016/S0031-3955(16)36839-0

4. Loh TF, Ang YH, Wong YK, Tan HY. Fallot's tetralogy-natural history. Singapore Med J. (1973) 14:169-71.

5. Bertranou EG, Blackstone EH, Hazelrig JB, Turner ME, Kirklin JW. Life expectancy without surgery in tetralogy of fallot. Am J Cardiol. (1978) 42:45866. doi: 10.1016/0002-9149(78)90941-4

6. Murphy JG, Gersh BJ, Mair DD, Fuster V, McGoon MD, Ilstrup DM, et al. Long-term outcome in patients undergoing surgical repair of tetralogy of fallot. N Engl J Med. (1993) 329:593-9. doi: 10.1056/NEJM199308263290901

7. Cuypers JA, Menting ME, Konings EE, Opic P, Utens EM, Helbing WA, et al. Unnatural history of tetralogy of fallot: prospective followup of 40 years after surgical correction. Circulation. (2014) 130:1944-53. doi: 10.1161/CIRCULATIONAHA.114.009454

8. Tatewaki H, Shiose A. Pulmonary valve replacement after repaired tetralogy of fallot. Gen Thorac Cardiovasc Surg. (2018) 66:509-15. doi: 10.1007/s11748-018-0931-0

9. Roos-Hesselink J, Perlroth MG, McGhie J, Spitaels S. Atrial arrhythmias in adults after repair of tetralogy of fallot. Correlations with clinical exercise and echocardiographic findings. Circulation. (1995) 91:2214-9. doi: 10.1161/01.CIR.91.8.2214

10. Sluman MA, Richard E, Bouma BJ, van Dalen JW, van Wanrooij LL, Groenink $M$, et al. Impact of structural cerebral damage in adults with tetralogy of fallot. Circulation. (2017) 135:1873-5. doi: 10.1161/CIRCULATIONAHA.117.027865

11. Majnemer A, Limperopoulos C, Shevell M, Rosenblatt B, Rohlicek C, Tchervenkov C. Long-term neuromotor outcome at school entry of infants with congenital heart defects requiring open-heart surgery. J Pediatr. (2006) 148:72-7. doi: 10.1016/j.jpeds.2005.08.036

12. Marino BS, Lipkin PH, Newburger JW, Peacock G, Gerdes M, Gaynor JW, et al. Neurodevelopmental outcomes in children with congenital heart disease: evaluation and management: a scientific statement from the American heart association. Circulation. (2012) 126:1143-72. doi: 10.1161/CIR.0b013e318265ee8a

13. Marelli A, Miller SP, Marino BS, Jefferson AL, Newburger JW. Brain in congenital heart disease across the lifespan: the cumulative burden of injury. Circulation. (2016) 133:1951-62. doi: 10.1161/CIRCULATIONAHA.115.019881

14. Claessens NHP, Chau V, de Vries LS, Jansen NJG, Au-Young SH, Stegeman $\mathrm{R}$, et al. Brain injury in infants with critical congenital heart disease: insights from two clinical cohorts with different practice approaches. J Pediatr. (2019) 215:75-82 e72. doi: 10.1016/j.jpeds.2019.07.017

15. Schellen C, Ernst S, Gruber GM, Mlczoch E, Weber M, Brugger PC, et al. Fetal MRI detects early alterations of brain development in tetralogy of fallot. Am J Obstet Gynecol. (2015) 213:392 e391-7. doi: 10.1016/j.ajog.2015.05.046

16. Claessens NHP, Algra SO, Ouwehand TL, Jansen NJG, Schappin R, Haas F, et al. Perioperative neonatal brain injury is associated with worse school-age neurodevelopment in children with critical congenital heart disease. Dev Med Child Neurol. (2018) 60:1052-8. doi: 10.1111/dmcn.13747

17. Algra SO, Jansen NJ, van der Tweel I, Schouten AN, Groenendaal F, Toet $\mathrm{M}$, et al. Neurological injury after neonatal cardiac surgery: a randomized, controlled trial of 2 perfusion techniques. Circulation. (2014) 129:224-33. doi: 10.1161/CIRCULATIONAHA.113.003312

18. Mavroudis CD, Karlsson M, Ko T, Hefti M, Gentile JI, Morgan RW, et al. Cerebral mitochondrial dysfunction associated with deep hypothermic circulatory arrest in neonatal swine. Eur J Cardiothorac Surg. (2018) 54:162-8. doi: 10.1093/ejcts/ezx467

19. Diaz LK, Gaynor JW, Koh SJ, Ittenbach RF, Gerdes M, Bernbaum JC, et al. Increasing cumulative exposure to volatile anesthetic agents is associated with poorer neurodevelopmental outcomes in children with hypoplastic left heart syndrome. J Thorac Cardiovasc Surg. (2016) 152:482-9. doi: 10.1016/j.jtcvs.2016.03.095
20. Galli KK, Zimmerman RA, Jarvik GP, Wernovsky G, Kuypers MK, Clancy RR, et al. Periventricular leukomalacia is common after neonatal cardiac surgery. $J$ Thorac Cardiovasc Surg. (2004) 127:692-704. doi: 10.1016/j.jtcvs.2003.09.053

21. Peyvandi S, Baer RJ, Moon-Grady AJ, Oltman SP, Chambers CD, Norton ME, et al. Socioeconomic mediators of racial and ethnic disparities in congenital heart disease outcomes: a population-based study in California. J Am Heart Assoc. (2018) 7:e010342. doi: 10.1161/JAHA.118.010342

22. Xiang L, Su Z, Liu Y, Huang Y, Zhang X, Li S, et al. Impact of family socioeconomic status on health-related quality of life in children with critical congenital heart disease. J Am Heart Assoc. (2019) 8:e010616. doi: 10.1161/JAHA.118.010616

23. McQuillen PS, Miller SP. Congenital heart disease and brain development. Ann N Y Acad Sci. (2010) 1184:68-86. doi: 10.1111/j.1749-6632.2009.05116.x

24. Miller SP, McQuillen PS, Hamrick S, Xu D, Glidden DV, Charlton N, et al. Abnormal brain development in newborns with congenital heart disease. $N$ Engl J Med. (2007) 357:1928-38. doi: 10.1056/NEJMoa067393

25. Clouchoux C, du Plessis AJ, Bouyssi-Kobar M, Tworetzky W, McElhinney DB, Brown DW, et al. Delayed cortical development in fetuses with complex congenital heart disease. Cereb Cortex. (2013) 23:2932-43. doi: 10.1093/cercor/bhs 281

26. Stiles J, Jernigan TL. The basics of brain development. Neuropsychol Rev. (2010) 20:327-48. doi: 10.1007/s11065-010-9148-4

27. Andropoulos DB, Hunter JV, Nelson DP, Stayer SA, Stark AR, McKenzie ED, et al. Brain immaturity is associated with brain injury before and after neonatal cardiac surgery with high-flow bypass and cerebral oxygenation monitoring. $J$ Thorac Cardiovasc Surg. (2010) 139:543-56. doi: 10.1016/j.jtcvs.2009.08.022

28. Bertholdt S, Latal B, Liamlahi R, Pretre R, Scheer I, Goetti R, et al. Cerebral lesions on magnetic resonance imaging correlate with preoperative neurological status in neonates undergoing cardiopulmonary bypass surgery. Eur J Cardiothorac Surg. (2014) 45:625-32. doi: 10.1093/ejcts/ezt422

29. Licht DJ, Shera DM, Clancy RR, Wernovsky G, Montenegro LM, Nicolson SC, et al. Brain maturation is delayed in infants with complex congenital heart defects. J Thorac Cardiovasc Surg. (2009) 137:529-36; discussion 536-27. doi: $10.1016 /$ j.jtcvs.2008.10.025

30. von Rhein M, Buchmann A, Hagmann C, Dave H, Bernet V, Scheer I, et al. Severe congenital heart defects are associated with global reduction of neonatal brain volumes. J Pediatr. (2015) 167:1259-63 e1251. doi: 10.1016/j.jpeds.2015.07.006

31. Mulkey SB, Ou X, Ramakrishnaiah RH, Glasier CM, Swearingen CJ, Melguizo MS, et al. White matter injury in newborns with congenital heart disease: a diffusion tensor imaging study. Pediatr Neurol. (2014) 51:377-83. doi: 10.1016/j.pediatrneurol.2014.04.008

32. Dimitropoulos A, McQuillen PS, Sethi V, Moosa A, Chau V, Xu D, et al. Brain injury and development in newborns with critical congenital heart disease. Neurology. (2013) 81:241-8. doi: 10.1212/WNL.0b013e3182 $9 \mathrm{bfdcf}$

33. Claessens NH, Moeskops P, Buchmann A, Latal B, Knirsch W, Scheer I, et al. Delayed cortical gray matter development in neonates with severe congenital heart disease. Pediatr Res. (2016) 80:668-74. doi: 10.1038/pr. 2016.145

34. Limperopoulos C, Tworetzky W, McElhinney DB, Newburger JW, Brown DW, Robertson RL Jr, et al. Brain volume and metabolism in fetuses with congenital heart disease: evaluation with quantitative magnetic resonance imaging and spectroscopy. Circulation. (2010) 121:26-33. doi: 10.1161/CIRCULATIONAHA.109.865568

35. Sur M, Rubenstein JL. Patterning and plasticity of the cerebral cortex. Science. (2005) 310:805-10. doi: 10.1126/science.1112070

36. Sun L, Macgowan CK, Sled JG, Yoo SJ, Manlhiot C, Porayette P, et al. Reduced fetal cerebral oxygen consumption is associated with smaller brain size in fetuses with congenital heart disease. Circulation. (2015) 131:1313-23. doi: 10.1161/CIRCULATIONAHA.114.013051

37. Kelly CJ, Christiaens D, Batalle D, Makropoulos A, Cordero-Grande L, Steinweg JK, et al. Abnormal microstructural development of the cerebral cortex in neonates with congenital heart disease is associated with impaired cerebral oxygen delivery. J Am Heart Assoc. (2019) 8:e009893. doi: 10.1161/JAHA.118.009893

38. Ge WP, Jia JM. Local production of astrocytes in the cerebral cortex. Neuroscience. (2016) 323:3-9. doi: 10.1016/j.neuroscience.2015.08.057 
39. Ortega JA, Sirois CL, Memi F, Glidden N, Zecevic N. Oxygen levels regulate the development of human cortical radial glia cells. Cereb Cortex. (2017) 27:3736-51. doi: 10.1093/cercor/bhw194

40. Kostovic I. Structural and histochemical reorganization of the human prefrontal cortex during perinatal and postnatal life. Prog Brain Res. (1990) 85:223-39; discussion 239-40. doi: 10.1016/S0079-6123(08)62682-5

41. Kostovic I, Jovanov-Milosevic N. The development of cerebral connections during the first 20-45 weeks' gestation. Semin Fetal Neonatal Med. (2006) 11:415-22. doi: 10.1016/j.siny.2006.07.001

42. Cavanna AE, Trimble MR. The precuneus: a review of its functional anatomy and behavioural correlates. Brain. (2006) 129(Pt. 3):564-83. doi: 10.1093/brain/awl004

43. Bruner E, Preuss TM, Chen X, Rilling JK. Evidence for expansion of the precuneus in human evolution. Brain Struct Funct. (2017) 222:1053-60. doi: 10.1007/s00429-015-1172-y

44. Leichnetz GR. Connections of the medial posterior parietal cortex (area 7m) in the monkey. Anat Rec. (2001) 263:215-36. doi: 10.1002/ ar.1082

45. Chen QL, Xu T, Yang WJ, Li YD, Sun JZ, Wang KC, et al. Individual differences in verbal creative thinking are reflected in the precuneus. Neuropsychologia. (2015) 75:441-9. doi: 10.1016/j.neuropsychologia.2015.07.001

46. Yin S, Zhu X, He R, Li R, Li J. Spontaneous activity in the precuneus predicts individual differences in verbal fluency in cognitively normal elderly. Neuropsychology. (2015) 29:961-70. doi: 10.1037/neu0000201

47. Zhuo CJ, Zhu JJ, Wang CL, Wang LN, Li J, Qin W. Increased local spontaneous neural activity in the left precuneus specific to auditory verbal hallucinations of schizophrenia. Chin Med J. (2016) 129:809-13. doi: 10.4103/0366-6999.178974

48. Borra E, Luppino G. Functional anatomy of the macaque temporo-parieto-frontal connectivity. Cortex. (2017) 97:306-26. doi: 10.1016/j.cortex.2016.12.007

49. Mondino M, Jardri R, Suaud-Chagny MF, Saoud M, Poulet E, Brunelin J. Effects of fronto-temporal transcranial direct current stimulation on auditory verbal hallucinations and resting-state functional connectivity of the left temporo-parietal junction in patients with schizophrenia. Schizophr Bull. (2016) 42:318-26. doi: 10.1093/schbul/sbv114

50. Catani M. The clinical anatomy of the temporal and parietal lobes. Cortex. (2017) 97:160-3. doi: 10.1016/j.cortex.2017.11.006

51. Jakab A, Meuwly E, Feldmann M, Rhein MV, Kottke R, O'Gorman Tuura R, et al. Left temporal plane growth predicts language development in newborns with congenital heart disease. Brain. (2019) 142:1270-81. doi: 10.1093/brain/awz067

52. Dong JW, Brennan NM, Izzo G, Peck KK, Holodny AI. fMRI activation in the middle frontal gyrus as an indicator of hemispheric dominance for language in brain tumor patients: a comparison with broca's area. Neuroradiology. (2016) 58:513-20. doi: 10.1007/s00234-016-1655-4

53. Lehericy S, Cohen L, Bazin B, Samson S, Giacomini E, Rougetet $\mathrm{R}$, et al. Functional MR evaluation of temporal and frontal language dominance compared with the Wada test. Neurology. (2000) 54:1625-33. doi: 10.1212/WNL.54.8.1625

54. Baldo JV, Shimamura AP, Delis DC, Kramer J, Kaplan E. Verbal and design fluency in patients with frontal lobe lesions. J Int Neuropsychol Soc. (2001) 7:586-96. doi: 10.1017/S1355617701755063

55. Pasquier F, Lebert F, Grymonprez L, Petit H. Verbal fluency in dementia of frontal lobe type and dementia of alzheimer type. J Neurol Neurosurg Psychiatry. (1995) 58:81-4. doi: 10.1136/jnnp.58.1.81

56. Tucha OW, Smely CW, Lange KW. Verbal and figural fluency in patients with mass lesions of the left or right frontal lobes. J Clin Exp Neuropsychol. (1999) 21:229-36. doi: 10.1076/jcen.21.2.229.928

57. Kambara T, Brown EC, Silverstein BH, Nakai Y, Asano E. Neural dynamics of verbal working memory in auditory description naming. Sci Rep. (2018) 8:15868. doi: 10.1038/s41598-018-33776-2

58. Mottaghy FM, Doring T, Muller-Gartner HW, Topper R, Krause BJ. Bilateral parieto-frontal network for verbal working memory: an interference approach using repetitive transcranial magnetic stimulation (rTMS). Eur J Neurosci. (2002) 16:1627-32. doi: 10.1046/j.1460-9568.2002.02209.x

59. Wexler BE, Anderson M, Fulbright RK, Gore JC. Preliminary evidence of improved verbal working memory performance and normalization of taskrelated frontal lobe activation in schizophrenia following cognitive exercises. Am J Psychiatry. (2000) 157:1694-7. doi: 10.1176/appi.ajp.157.10.1694

60. Troyer AK, Moscovitch M, Winocur G, Alexander MP, Stuss D. Clustering and switching on verbal fluency: the effects of focal frontaland temporal-lobe lesions. Neuropsychologia. (1998) 36:499-504. doi: 10.1016/S0028-3932(97)00152-8

61. Schulke R, Straube B. Modulating the assessment of semantic speech-gesture relatedness via transcranial direct current stimulation of the left frontal cortex. Brain Stimul. (2017) 10:223-30. doi: 10.1016/j.brs.2016.10.012

62. Liu CL, Hue CW, Chen CC, Chuang KH, Liang KC, Wang $\mathrm{YH}$, et al. Dissociated roles of the middle frontal gyri in the processing of Chinese characters. Neuroreport. (2006) 17:1397-401. doi: 10.1097/01.wnr.0000233090.00463.35

63. Robinson GA, Cipolotti L, Walker DG, Biggs V, Bozzali M, Shallice T. Verbal suppression and strategy use: a role for the right lateral prefrontal cortex? Brain. (2015) 138(Pt. 4):1084-96. doi: 10.1093/brain/awv003

Conflict of Interest: The authors declare that the research was conducted in the absence of any commercial or financial relationships that could be construed as a potential conflict of interest.

Copyright (C) $2020 \mathrm{Ma}$, Li, Liu, Xu, Li, Yao, Wang, Yang, Zuo, Yang and Mo. This is an open-access article distributed under the terms of the Creative Commons Attribution License (CC BY). The use, distribution or reproduction in other forums is permitted, provided the original author(s) and the copyright owner(s) are credited and that the original publication in this journal is cited, in accordance with accepted academic practice. No use, distribution or reproduction is permitted which does not comply with these terms. 